\title{
Transcultural adaptation and validation of the CRAFFT as a screening test for problematic alcohol and substance use, abuse and dependence in a group of Argentine adolescents
}

\author{
María Carolina Bertini, M.D., ${ }^{a}$ Julio Busaniche, M.D., ${ }^{a}$ Ferney Baquero, M.D., ${ }^{a}$ \\ Alfredo Eymann, M.D., " Mariana Krauss, M.D., ${ }^{a}$ Marcela Paz, M.D., ${ }^{a}$ and \\ Cristina Catsicaris, M.D. ${ }^{a}$
}

\begin{abstract}
Introduction. Substance use and abuse and their consequences are a major problem among adolescents. Thescreening for problematicalcohol and substance use, abuse and dependence should be part of the case-taking process for adolescents. The Problem Oriented Screening Instrument for Teenagers (POSIT) and the Car, Relax, Alone, Forget, Family/Friends, Trouble questionnaire (CRAFFT) are used to this end. POSIT: 17 items corresponding to substance use and abuse $\left(\right.$ POSIT $\left._{\text {sua }}\right)$; it has been validated in Spanish. CRAFFT: six questions; it has not been validated in Argentina.

Objective. To assess the validity of a version of the CRAFFT screening test adapted to Spanish in a group of Argentine adolescents using the POSIT $_{\text {sua }}$ test as reference.

Population and Methods. The CRAFFT $\mathrm{a}$ and the POSIT tests were administered to 14-20 year-old adolescents. An affirmative answer was scored as 1, and a negative answer, as 0 . An individual was considered to have an increased risk of problematic use, abuse and dependence if he/ she scored $\geq 2$ in the CRAFFT $a$ and POSIT sua tests.

Results. Twohundred and eighty-six adolescents were included; $52 \%$ were female; mean age: 16.6 years old. The CRAFFT a $_{\text {a }}$ score was $\geq 2$ for $29 \%$, while the POSIT sua score was $\geq 2$ for $37 \%$. CRAFFT a sensitivity: $59 \%$; specificity: $88 \%$. CRAFFT a positive predictive value: 0.74 ; negative predictive value: 0.78 . The area under the curve was 0.73 . In the linear regression, the $\mathrm{R}^{2}$ for the six CRAFFT questions was 0.60. Gender and age did not modify results. Cronbach's alpha was 0.64 .

Conclusion. CRAFFT a sensitivity was $59 \%$, and its specificity was $88 \%$, compared to the POSIT test as a screening tool for problematic alcohol and substance use, abuse and dependence among Argentine adolescents.

Key words: adolescent, substance abuse screening,
\end{abstract} substance-related disorders.

http:/ /dx.doi.org/10.5546/aap.2015.eng.114

\section{INTRODUCTION}

Substance use and abuse and their consequences are a major problem among adolescents. According to the
Fifth National Secondary Student Survey, alcohol abuse is the main problem of consumption among adolescents in Argentina. It is also alarming how marihuana use has increased among adolescents in recent years. ${ }^{1}$

The consumption of psychoactive substances during adolescence harms the psychophysical health, even before the addiction is developed. ${ }^{2}$ Additionally, adolescence is a stage of neurodevelopment, and drugs may act on the reward system in the brain. The younger the age at initiation, the greater the probability of developing a substance use disorder (problematic use, abuse or dependence). ${ }^{2}$

Pediatricians play an important role in the prevention, detection and management of adolescents' integral health. ${ }^{2}$

Studies have shown that, when based on our own impression, we tend to underestimate the risk posed by problems related to psychoactive substance use among our patients.,

Using structured screening tools when evaluating a patient improves the detection of adolescent substance use disorders. Several screening tools have been developed; the ones most widely used for adolescents are the POSIT and the CRAFFT screening tests.

The POSIT is a questionnaire used to detect specific problems in different performance areas of adolescents. The screening for problematic substance use, abuse and dependence consists of 17 questions (POSIT ${ }_{\text {sua }}$ ) (Annex 1). It is completed in writing and has been validated in English and in Spanish. ${ }^{5-7}$ 
The CRAFFT is a screening test to assess the risk of problematic alcohol and substance use, abuse or dependence among adolescents. Its acronym is based on six key words that make up the test aspects: car, relax, alone, forget, family / friends, and trouble (Annex 2).

Knowing that the CRAFFT test has neither been adapted nor validated in Argentina, we proposed to adapt it to Spanish and test its validity to detect problematic alcohol and substance use, abuse and dependence among Argentine adolescents.

\section{OBJECTIVE}

To assess the validity of a version of the CRAFFT screening test adapted to Spanish in a group of Argentine adolescents using the POSIT screening test as reference.

\section{POPULATION AND METHODS}

Design: observational, cross sectional study.

Population: Argentine adolescents aged 14 to 20 years old who attended a scheduled or spontaneous appointment at the Department of Adolescence of Hospital Italiano de Buenos Aires between October 2011 and February 2013, time when the estimated sample size was attained.

Sample size: given an estimated adolescent population of 5000 individuals who attend the Department of Adolescence every year, an estimated prevalence of alcohol use of $27 \%$ and a $5 \%$ margin error, the sample size estimated was 280 patients.

Exclusion criteria: adolescents with developmental delay or mental retardation, who did not speak or understand Spanish, or who had a psychiatric disorder that prevented them from participating in the study.

Transcultural adaptation: the CRAFFT questionnaire consists of two parts. Part A includes three questions on alcohol, marihuana and other drugs used in the past 12 months. If any of these three questions is answered affirmatively, Part B is completed, which is made up of six yesno questions (Annex 2).

We first contacted the questionnaire authors (Dr. Knight, et al. $)^{4}$ and requested their approval to use the CRAFFT test in this study. We then had it translated into Argentine Spanish by a certified translator and by a bilingual professional. Once both translations into Spanish were received, they were unified into the $\mathrm{CRAFFT}_{\mathrm{a}}$ (Annex 3). Two independent back-translations into English were then requested. The English versions were unified and compared to the original version, and the final version was approved by the original authors.

The CRAFFT C $_{\mathrm{a}}$ questionnaire was tested in a sample of 15 adolescents to check all items were correctly stated and to gather any feedback they might have. No modifications were necessary.

Validation: CRAFFT $_{\mathrm{a}}$ and the POSIT $_{\text {sua }}$ results were compared.

During the visit, the doctor informed his/ her adolescent patients on the study objective and handed him/her in three documents: the informed consent form (Annex 4), the CRAFFT test (Annex 3) and the POSIT sua test (Annex 1). Surveys were anonymous and completed by adolescents themselves.

Written consent was obtained exclusively from adolescents (not from their parents or caregivers), with due regard to their autonomy, privacy and confidentiality (Convention on the Rights of the Child, National Law 26061, and National Law 26529).

Both tests assigned a score of 1 for "Yes" answers and 0 for "No" answers. Individuals were considered to have a risk of problematic substance use, abuse or dependence if they scored a total of 2 or more, both in the CRAFFT $\mathrm{C}_{\mathrm{a}}$ and the POSIT $_{\text {sua }}$ tests, respecting the cut-off point established by the original authors of both tests.

Sensitivity, specificity, positive predictive value and negative predictive value were

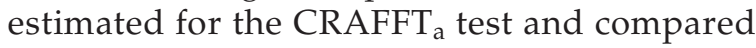
to the POSIT sua test, and the area under the curve for a cut-off point of two affirmative answers out of six. The correlation between the CRAFFT $a$ test and the POSIT sua test was estimated, with a linear regression analysis that included the $\mathrm{CRAFFT}_{\mathrm{a}}$ six items; Cronbach's alpha was used to analyze its internal consistency.

Statistical analysis: the Stata 8.0 software (Stata Corporation, Texas, USA) was used.

Ethical considerations: the study protocol was approved by the Research Protocol Ethics Committee of Hospital Italiano de Buenos Aires on November $24^{\text {th }}, 2011$.

\section{RESULTS}

The study included 290 adolescents; 286 completed both questionnaires adequately. No adolescent refused to take part. Fifty-two percent (148) were female. Their mean age was 16.6 (range: 14 to 20) years old. One hundred percent attended school; 98.6\% (282) attended a highschool or had finished it and $2 \%$ were attending a primary school. 
A score of 2 or more was obtained by $29 \%$ (83) (confidence interval [CI]: 23.7-34.3) of adolescents in the CRAFFT ${ }_{a}$ test, and by 37\% (106) (CI: 31.442.7) in the POSIT $_{\text {sua }}$ test.

Compared to the POSIT sua' $_{\text {, }}$ the CRAFFT sensitivity and specificity were $59 \%$ and $88 \%$, respectively. The CRAFFT ${ }_{a}$ positive predictive value was 0.74 , while its negative predictive value was 0.78 . The area under the curve (ROC) with a cut-off point of 2 was $0.73(0.68-0.79) ; 77.3 \%$ of individuals were correctly classified.

In the linear regression analysis, taking the overall score of the POSIT sua test as a dependant outcome measure, the $\mathrm{R}^{2}$ for the six items was 0.60 . It was not modified when excluding question 3 (alone), but it was slightly modified (0.58) when excluding question 1 (car). The linear regression model showed that a model of four questions (relax, forget, family / friends, and trouble) shows practically the same correlation $\left(R^{2}=0.58\right)$ than the six CRAFFT ${ }_{a}$ questions (see Table 1). Gender and age do not modify results.

When analyzed separately, the question that best related to the POSIT test was question 4 (forget), $\mathrm{R}^{2}=0.33$, followed by question 5 (family/ friends), $R^{2}=0.27$. The test's internal consistency measured using Cronbach's alpha was 0.64.

\section{DISCUSSION}

In our study, following a transcultural adaptation, we validated the CRAFFT questionnaire in a group of Argentine adolescents.

In this study, we compared the CRAFFT $\mathrm{a}_{\mathrm{a}}$ and

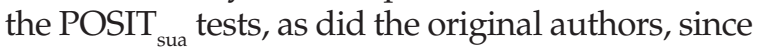

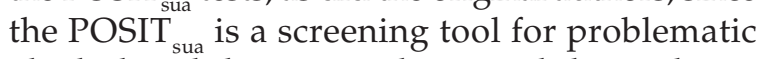
alcohol and drug use, abuse and dependence among adolescents. This tool has already been validated in Spanish. ${ }^{5-7}$ Knight, et al. also used a diagnostic structured interview based on the DSM-IV criteria for alcohol and drug abuse and dependence to validate the CRAFFT test. ${ }^{8} \mathrm{We}$ were not able to use the psychiatric interview as reference.

The CRAFFT questionnaire (Annex 3) indicates that if Part $\mathrm{A}$ is negative (i.e., all questions are answered as "No"), individuals should continue to question 1, Part B, to detect adolescents who

TABLE 1. CRAFFTa linear regression using 6 items/4 items

\begin{tabular}{lccc}
\hline Items & R2 adjusted & R2 standard & deviation \\
\hline 6 & 0.5902 & 0.5892 & 1.0593 \\
4 & 0.5823 & 0.5762 & 1.0762 \\
\hline
\end{tabular}

have been at risk of riding in a car driven by a person under the influence of alcohol or drugs. Although we recommend to use this design at the outpatient office, we decided to exclude it and to have participants who answered "Yes" to at least one of the questions in Part A complete Part B (leaving aside all those who answered "No" to all questions in Part A). This means that we included adolescents who had used substances in the past 12 months. The objective of this study is to assess the construct made up by the six questions in Part B of the $\mathrm{CRAFFT}_{\mathrm{a}}$ test to detect problematic use, abuse and dependence, and to estimate its sensitivity, specificity and internal consistency.

The American Academy of Pediatrics recommends to inquire about psychoactive substance use, including alcohol, tobacco and other drugs, during the case-taking process for patients, at least once a year, and to screen those who have used some substance (alcohol or other substances of abuse) using a validated instrument, such as the CRAFFT test, to establish the risk of problematic use, abuse or dependence. ${ }^{2}$

An increased risk (i.e., a score of 2 or more) in the CRAFFT test indicates the pediatrician that the patient requires a more comprehensive and detailed assessment regarding substance use, and this assessment will help determine the approach: counseling, brief intervention, consultation with or referral to the Department of Mental Health, or a specialized treatment. ${ }^{8}$

Compared to other screening tests, such as the Alcohol Use Disorders Identification Test (AUDIT), the Cut Down, Annoyed, Guilty and Eye Opener (CAGE) and the Michigan Alcohol Screening Test (MAST), the advantages of the CRAFFT test include the fact that it can be administered orally, there are no differences in terms of gender or ethnicity, it is useful with drugs other than alcohol, and it is speciallydesigned for the adolescent population. ${ }^{10-12}$ Compared to the POSIT test, the CRAFFT test is more brief and may be conducted orally.

The relationship between a tool and the cultural setting where it has been developed is the result of specific parameters, such as cultural habits, customs and beliefs, which largely impose how to ask questions, what the most adequate terms are, as well as what the meaning of words and phrases are. ${ }^{13}$

There is a Spanish version of the CRAFFT test called CARLOS, ${ }^{14}$ but it has not been validated in Argentina. We decided to use the original version in English and make our own transcultural 
adaptation according to internationally agreed steps. $^{15}$

In our study, $29 \%$ of adolescents who used alcohol, marihuana or other drugs in the past

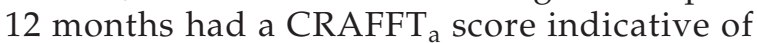
an increased risk of problematic alcohol or drug use, abuse and dependence, and this percentage was similar to that reported by Knight, et al., who found that $25 \%$ of participants had a CRAFFT score of 2 or more. ${ }^{8}$

In our study, the CRAFFT a sensitivity (59\%) was lower than that observed by the original authors $(80 \%$ and $92 \%)$. Its specificity $(88 \%)$ was similar to that reported by them ( $82 \%$ and $86 \%)$. Its positive and negative predictive values $(0.74$ and 0.78 , respectively) were somewhat lower than those described in other studies (0.83 and 0.91). The test's internal consistency (0.64) was similar to that reported by the original authors $(0.68) .{ }^{8,16}$

We believe that the lower sensitivity of the CRAFFT $_{a}$ test compared to that described by the CRAFFT test authors may be due to the different populations and to the fact that questions related to "car" and "alone" had little impact in the screening process. This is probably because, in Argentina, driver's licenses are obtained at an older age than in other countries where the CRAFFT test has been studied, and because psychoactive substance use among adolescents usually takes place in a group. ${ }^{1}$

In the linear regression analysis, the $\mathrm{CRAFFT}_{\mathrm{a}}$ test showed an adequate correlation with the POSIT $_{\text {sua }}$ test $\left(R^{2}=0.60\right)$, but it was somewhat lower than that reported by the original authors $\left(R^{2}=0.68\right)$. When validating the instrument, they did not find any gender or age influence either. ${ }^{8}$

In relation to the cut-off point, we also found a greater sensitivity and specificity and a better area under the curve (ROC) with two positive questions from the CRAFFT ${ }_{\mathrm{a}}$ test, as did Knight, et al. ${ }^{8}$

In our study, a linear regression model showed that a model of four questions (relax, forget, family and friends, and trouble) had almost the same correlation than the six CRAFFT questions (0.58 versus 0.60 ). Therefore, in our study population, the questions related to "car" and "alone" had little influence on the screening for problematic alcohol and drug use, abuse and dependence.

So, in our setting, the four-question model for the CRAFFT ${ }_{a}$ test (relax, forget, family/friends, and trouble) could be used. The analysis of the sensitivity and specificity of this model and the establishment of its cut-off point remain to be defined. Future research should also focus on how the inclusion of other questions may improve the sensitivity of this screening test.

Our results cannot be extrapolated to the entire Argentine population because the studied population has access to social security and private health insurance and their education level is high compared to the mean level observed in Argentina. It is necessary to conduct other studies to assess how the CRAFFT C $_{a}$ test would perform in different sociocultural settings in the country.

We believe the CRAFFT $a$ test could be included as part of interviews with adolescents. It does not replace personal questions that the pediatrician may ask his/her patient; on the contrary, the casetaking process is thus enriched since it has been demonstrated that medical intuition may, in fact, underestimate the actual risk. ${ }^{2}$

As per our judgment, the CRAFFT a test could be a valid instrument to be used by pediatricians or health professionals who work with adolescents to screen for problems related to alcohol and drug use, even if its sensitivity is lower than that previously reported. Its ease of use favors its inclusion during the case-taking process for adolescents.

It is necessary to conduct other studies to assess how the CRAFFT $\mathrm{C}_{\mathrm{a}}$ test would perform in different sociocultural settings in the country.

\section{CONCLUSION}

In this study, we have validated a version of the CRAFFT screening test adapted to Spanish in a group of Argentine adolescents using the POSIT $_{\text {sua }}$ screening tool as reference.

Compared to POSIT $_{\text {sua, }}$ the CRAFFT sensitivity was $59 \%$, and its specificity was $88 \%$. Its positive predictive value was 0.74 , while its negative predictive value was 0.78 .

\section{REFERENCES}

1. SEDRONAR, Observatorio Argentino de Drogas. Quinta Encuesta Nacional a Estudiantes de Enseñanza Media 2011. Informe final de resultados. Buenos Aires: SEDRONAR; 2012. Available at: http://www.observatorio.gov.ar/ investigaciones /Quinta\%20Encuesta\%20Nacional\%20 a\%20Estudiantes\%20de\%20Enseñanza\%20Media\%202011. pdf. [Accessed on: March 4, 2013].

2. Committee on Substance Abuse, Levy SJ, Kokotailo PK. Substance use screening, brief intervention, and referral to treatment for pediatricians. Pediatrics 2011;128(5):e1330-40.

3. Levy S, Knight JR. Office-Based Management of Adolescent Substance Use and Abuse. En Neinstein LS, Gordon CM, Katzman DK, Rosen DS, Woods ER, eds. Adolescent Health Care: A Practical Guide. 5th ed. Philadelphia, EE. UU.: Lippincott Williams \& Wilkins; 2008. Págs. 949-58. 
4. Wilson CR, Sherritt L, Gates E, Knight JR. Are clinical impressions of adolescent substance use accurate? Pediatrics 2004;114(5):e536-40.

5. Rahdert ER. Problem Oriented Screening Instrument for Teenagers (POSIT). En: Rahdert ER, ed. The Adolescent assessment/referral system manual. Rockville, MD: National Institute on Drug Abuse; 1991. Págs. 67-8.

6. Knight JR, Goodman E, Pulerwitz T, DuRant RH. Reliability of the Problem Oriented Screening Instrument for Teenagers (POSIT) in adolescent medical practice. J Adolesc Health 2001;29(2):125-30.

7. Mariño MC, González Forteza C, Andrade P, Medina Mora ME. Validación de un cuestionario para detectar adolescentes con problemas por el uso de drogas. Salud Ment 1998;21(1):27-36.

8. KnightJR,SherrittL,Shrier LA,Harris SK, etal. Validity of the CRAFFT substance abuse screening test among adolescent clinic patients. Arch Pediatr Adolesc Med 2002;156(6): 607-14.

9. Center for Adolescent Substance Abuse Research. The CRAFFT Screening Interview. Boston: Children's Hospital Boston; 2009. Available at: http:/ / www.ceasar-boston.org/ CRAFFT/pdf/CRAFFT_English.pdf. [Accessed on:June 20, 2011].

10. Knight JR, Sherritt L, Harris SK, Gates EC, et al. Validity of brief alcohol screening tests among adolescents: a comparison of the AUDIT, POSIT, CAGE, and CRAFFT. Alcohol Clin Exp Res 2003;27(1):67-73.
11. Kelly TM, Donovan JE, Chung T, Bukstein OG, et al. Brief screens for detecting alcohol use disorder among 18-20 year old young adults in emergency departments: comparing AUDIT-C, CRAFFT, RAPS4-QF, FAST, RUFT-Cut, and DSM-IV 2-Item Scale. Addict Behav 2009;34(8):668-74.

12. Cook RL, Chung T, Kelly TM, Clark DB. Alcohol screening in young persons attending a sexually transmitted disease clinic. Comparison of AUDIT, CRAFFT, and CAGE instruments. J Gen Intern Med 2005;20(1):1-6.

13. PaneS,SolansM, Gaite L,Serra-Sutton V,etal. Instrumentos de calidad de vida relacionada con la salud en la edad pediátrica. Revisión sistemática de la literatura: actualización. Barcelona: Agencia de Evaluación de Tecnología eInvestigación Médicas; 2006. Available at: http://www.pediatrasandalucia.org/ Docs/CalidadVidaPediatrico.pdf. [Accessed on:August20, 2014].

14. Center for Adolescent Substance Abuse Research. Las Preguntas CARLOS(CRAFFT). Boston:Children's Hospital Boston; 2009. Available at: http:/ /www.ceasar-boston.org/ CRAFFT/pdf/CRAFFT_SA_Spanish.pdf. [Accessed on: August 20, 2014].

15. Arribas A. Adaptación transcultural de instrumentos. Guía para el proceso de validación de instrumentos tipo encuestas. Rev Asoc Med Bahia Blanca 2006;16(3):74-82.

16. Knight JR, Shrier LA, Bravender TD, Farrell M, et al. A new brief screen for adolescent substance abuse. Arch Pediatr Adolesc Med 1999;153(6):591-6. 


\section{ANNEX 1. PROBLEM ORIENTED SCREENING INSTRUMENT FOR TEENAGERS (POSITsua)}

The purpose of these questions is to help us choose the best way to help you. So, please try to answer the questions honestly.

This is not a test; there are no right or wrong answers. All answers will be confidential.

Please answer all of the questions. If a question does not fit you exactly, pick the answer that is mostly true. Please put an " $X$ " on your answer.

If you do not understand a word, please ask for help to the person in charge.

Thank you!

1. Do you get into trouble because you use drugs or alcohol at school?

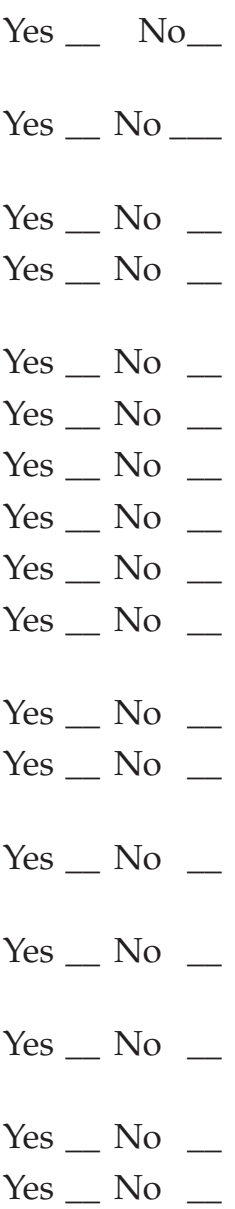

2. Have you accidentally hurt yourself or someone else while high on alcohol or drugs?

3. Do you miss out on activities because you spend too much money on drugs or alcohol?

4. Do you ever feel you are addicted to alcohol or drugs?

5. Have you started using more and more drugs or alcohol to get the effect you want?

6. Do you ever leave a party because there is no alcohol or drugs?

7. Do you have a constant desire for alcohol or drugs?

8. Have you ever had a car accident while high on alcohol or drugs?

9. Do you forget things you did while drinking or using drugs?

10. During the past month, have you driven a car while you were drunk or high?

11. Does alcohol or drug use cause your moods to change quickly like from happy to sad or vice versa?

12. Do you miss school or arrive late for school because of your alcohol or drug use?

13. Do your family or friends ever tell you that you should cut down on your drinking or drug use?

14. Do you have serious arguments with friends or family members because of your drinking or drug use?

15. Does your alcohol or drug use ever make you do something you would not normally do, like breaking rules, missing curfew or breaking the law?

16. Do you have trouble getting along with any of your friends because of your alcohol or drug use?

17. Do you ever feel you can't control your alcohol or drug use?

Yes - No -




\section{ANNEX 2. CRAFFT QUESTIONNAIRE}

\section{The CRAFFT Screening Questions}

Please answer all questions honestly; your answers will be kept confidential.

\section{Part $A$}

During the PAST 12 MONTHS, did you:

1. Drink any alcohol (more than a few sips)?

2. Smoke any marijuana or hashish?

3. Use anvthing else to get high?

"anything else" includes illegal drugs, over the counter and prescription drugs, and things that you sniff or "huff"
No

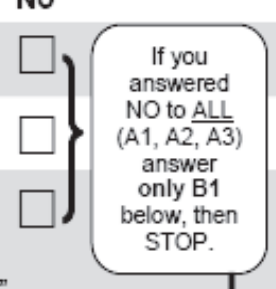

Yes

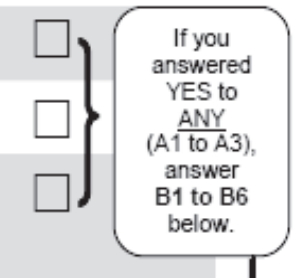

\section{Part B}

No

Yes

1. Have you ever ridden in a CAR driven by someone (including yourself) who was "high" or had been using alcohol or drugs?

2. Do you ever use alcohol or drugs to RELAX, feel better about yourself, or fit in?

3. Do you ever use alcohol or drugs while you are by yourself, or ALONE?

4. Do you ever FORGET things you did while using alcohol or drugs?

5. Do your FAMILY or FRIENDS ever tell you that you should cut down on your drinking or drug use?

6. Have you ever gotten into TROUBLE while you were using alcohol or drugs? 


\section{ANNEX 3. ARGENTINE VERSION OF THE CRAFFT QUESTIONNAIRE: CRAFFTa}

PART A

During the past 12 months, did you:

1. Drink any alcohol (more than a few sips)?

$\begin{array}{ll}\text { Yes_- } & \mathrm{No}_{-} \\ \text {Yes_- } & \text { No__ } \\ \text { Yes_- } & \text { No__ }\end{array}$

2. Smoke any marihuana?

3. Use any other substance to change your mood or consciousness?*

* "Any other substance" means illegal drugs, over the counter and prescription drugs, and substances you sniff to change your mental status.

(If you answered "Yes" to ANY of the 3 questions above, go to questions B1-B6).

\section{PART B}

1. Have you ever ridden in a vehicle driven by you or someone else who had been using alcohol or drugs?

\begin{tabular}{|c|}
\hline Yes__ \\
\hline Yes__ \\
\hline Yes__ \\
\hline Yes_- \\
\hline Yes_- \\
\hline 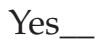 \\
\hline
\end{tabular}

2. Have you ever used alcohol or drugs to relax, feel better about yourself or fit in?

3. Have you ever used alcohol or drugs while you were alone?

4. Have you ever forgotten things you did while drinking or using drugs?

5. Have your family or friends ever told you that you should cut down on your drinking or drug use?

6. Have you ever gotten into trouble because you were using alcohol or drugs?

Yes

No 


\section{ANNEX 4. INFORMED CONSENT}

Buenos Aires, $201 \ldots$

1. We would like to invite you to take part in the study titled: "Validation of the CRAFFT as screening test for substance use and abuse among Argentine adolescents," which is being conducted by the doctors of the Department of Adolescence of Hospital Italiano de Buenos Aires.

2. The objective of this study is to validate a questionnaire used in other countries to detect youth your age who may be having problems with alcohol and/or drug use.

3. The questionnaire is made up of six questions that you must answer with "Yes" or "No" based on what you consider best fits your case. This is not a test, so there are no right or wrong answers.

4. The questionnaire is anonymous and you must complete it on your own (with no help from your parents, siblings, boyfriend/girlfriend, etc.). You do not have to write any information that may identify you.

5. Remember that, even if you are under 18 years old, you have a right to have your information be kept confidential and that no one has to know about it, unless you agree to share it. If you think you have a problem with alcohol and/or drugs, we offer interviews with specialists from the Department of Mental Health of Hospital Italiano de Buenos Aires and we will find a way to help you.

6. Before you agree to participate in this study, please ask any question you may have and we will answer them. If you have any other concern, you can write to Doctor Ferney Baquero, from the Department of Adolescence, at ferney.baquero@hospitalitaliano.com.

7. You do not have to participate if you do not want to; it is your decision. You may agree now and then change your mind. You just have to tell us. No one will get mad at you and you will still receive any medical care you need.

8. This study was evaluated by the Research Protocol Ethics Committee of Hospital Italiano de Buenos Aires (CEPI).

9. If you agree to participate in this study, please sign below. A copy of this form will be given to you so that you keep it.

Print name:

ID number:

Print name:

ID number:

(Doctor)
Print name:

ID number:

(Witness) 